\title{
CLINICAL EVALUATION AND TREATMENT OF ACUTE ASTHMA EXACERBATIONS IN CHILDREN
}

L. INDINNIMEO, F. BERTUOLA, R. CUTRERA², F.M. DE BENEDICTIS ${ }^{3}$, P. DI PIETRO ${ }^{4}$, M. DUSE, P. GIANIORIO ${ }^{4}$, G. INDIRLI ${ }^{5}$, S. LA GRUTTA ${ }^{6}$, M. LA ROSA 7 , R. LONGHI', S. MICELI SOPO ${ }^{9}$, P. MIGLIORANZI ${ }^{10}$, M. MIRAGLIA DEL GIUDICE ${ }^{11}$, F. MONACO, D. RADZIK ${ }^{12}$, S. RENNA ${ }^{4}$, D. SNIJDERS ${ }^{1}$, S. ZAMPOGNA ${ }^{13}$ and A. BARBATO ${ }^{1}$

Department of Pediatrics "Sapienza" University of Rome; ${ }^{~}$ Department of Pediatrics, University of Padua; ${ }^{2}$ Pediatric Hospital Bambino Gesù, Rome; ${ }^{3}$ Pediatric Unit, Salesi Hospital, Ancona; ${ }^{4}$ Children's Hospital

G. Gaslini Institute, Genova; ${ }^{5}$ Pediatric Unit, San Giuseppe da Copertino Hospital; ${ }^{6}$ CNR of Palermo; ${ }^{7}$ Department of Pediatrics, University of Catania; ${ }^{8}$ Pediatric Unit, Sant'Anna Hospital, Como; ${ }^{9}$ Department of Pediatrics, Catholic University of Rome; ${ }^{10}$ Italian Federation of Family Pediatricians; ${ }^{11}$ Department of Pediatrics, $2^{\text {nd }}$ Universiy of Naples; ${ }^{12}$ Pediatric Unit, S. Giacomo Hospital, Castelfranco Veneto; ${ }^{13}$ Pediatric Unit, "Pugliese-Ciaccio" Hospital, Catanzaro, Italy

Received December 12, 2008 - Accepted September 11, 2009

This update on treatment of asthma exacerbations in children is the result of an Italian Pediatric Society Task-force, made up of a panel of experts working in 2007-2008. The aim is to give clear indications on the use of the drugs most employed in children, grading the quality of evidence and the strength of recommendations. Suggestions on their limits due to unlicensed and off-label use are reported. The level of evidence and the strength of recommendations for different therapeutic approaches demonstrate that frequently the use of drugs in children is extrapolated from the experience in adults and that more studies are required to endorse the correct use of different drugs in asthmatic children.

Over the last decade, a number of clinical practice guidelines that include guidance for the management of pediatric asthma have been introduced. (1-3). The consistency of pediatric asthma guidelines is unknown and the emphasis on establishing asthma control may vary. The objective of this paper on acute asthma exacerbations in children is to report the work of a Task-force constituted of a panel of experts, members of the Italian Paediatric Society, working in 2007-2008. It was elaborated to provide recent information to all caregivers of asthmatic children, from the family paediatricians to the nurses and physicians working in Emergency Departments
(ED). This report grades the quality of evidence and the strength of recommendations for the diagnosis and treatment of acute asthma in children. Recommendations may be defective because, in children, the use of unlicensed and off-label drugs at doses extrapolated from studies performed only in adults is frequent. This aspect may be a potential starting point for clinical research in order to improve the treatment of children with acute asthma exacerbations.

This update aims to focus on the approach to acute asthma exacerbations from the diagnostic and therapeutic point of view.

Key words: children, acute asthma, emergency treatment

\footnotetext{
Mailing address: Dr Luciana Indinnimeo,

"Sapienza"University of Rome,

Department of Pediatrics,

Umberto I Hospital,

Viale Regina Elena, 32400161 Rome, Italy

Fax: ++390498213502

luciana.indinnimeo@uniroma1.it
}

0394-6320 (2009)

Copyright $(\odot$ by BIOLIFE, s.a.s. This publication and/or article is for individual use only and may not be further reproduced without written permission from the copyright holder. Unauthorized reproduction may result in financial and other penalties 


\section{METHODS}

From 2007 until the end of 2008, the Task Force was constituted of a panel of experts, members of the Italian Paediatric Society, who evaluated articles from The Cochrane Register of Controlled Trials (CENTRAL), PubMed, EMBASE, the lists of references in relevant publications, and the authors' collection of references. Information regarding drugs mentioned in the paper are available on the website: http://emc.medicines.org.uk; however, license regulations may vary among countries and readers are invited to consult their national regulations.

Evidence levels were graded as proposed by the BMJClinicalEvidenceGrading ofRecommendations, Assessment, Development and Evaluation (GRADE) working group (1). The GRADE score system takes into account the type of evidence, the quality, the consistency, the directness and the size of the effect; evidence was classified as low, fair, moderate, high or expert opinion; benefits were described as none, conflicting, small/weak, intermediate or substantial; strength of recommendation was classified as strong or weak (Table I) (1).

Acute asthma is defined as an acute exacerbation of wheezing, unresponsive to usually effective therapy and necessitating care in an emergency room or hospital ward. An acute asthma attack is characterized by airway narrowing and inflammation, hyperinflation, impairment of pulmonary function, alterations in alveolar ventilation and hypoxemia.

Attacks of wheezing induced by upper respiratory viral infections are common in pre-school children and can be confused with acute asthma exacerbations, but they have different treatment strategies.

\section{CLINICAL EVALUATION}

Quick and careful clinical evaluation of the child, made to assess the severity of acute asthma, is essential to develop a therapeutic plan. Anamnestic and clinical parameters are fundamental to evaluate the patient, even if they have little correlation to the severity of each asthma episode (Table II), therefore it is necessary to monitor: O2 Saturation $(\mathrm{SaO} 2)(\%)$, Peak Expiratory Flow (PEF) or Forced Expiratory Volume at 1 second (FEV1) and in severe cases
Partial Arterial CO2 Pressure (Pa CO2) (4-6).

In children who are not able to perform spirometric monitoring, a close clinical monitoring should be effectuated to establish the severity of asthma. Not all parameters of severity score need to be fulfilled to classify asthma severity.

Mild asthma exacerbations, according to the suggestions of a recent ATS/ERS task force was not taken into consideration in this paper, because symptoms or changes in flow rates may reflect transient loss of asthma control rather than the early stages of severe exacerbation. (7)

\section{Recommendation}

1. In children with acute asthma exacerbation $\mathrm{SaO} 2, \mathrm{PEF}$ or FEV1 and, in severe cases, $\mathrm{Pa}$ $\mathrm{CO} 2$ should be evaluated to establish the grade of severity. Level of evidence high; benefits were substantial; strength of recommendation strong (1B).

Great attention must be paid to factors associated with severe asthma exacerbations such as previous admission to PICU, two or more admissions or visits in ED in the last year, usual and/or recurrent use of systemic corticosteroids, increased need for bronchodilator therapy during the last weeks or months, low social economic conditions, etc.

\section{TREATMENT}

\section{Oxygen therapy}

The administration of oxygen should be regulated by pulse oximetry; children with $\mathrm{SaO} 2<92 \%$ should receive humidified oxygen by facemask, or nasal cannula with sufficient flow to achieve and maintain a normal oxygen saturation $(\geq 95 \%)(4,8-9)$. In a review (9) of several randomised clinical studies (RCS), in which a placebo replaced oxygen therapy, it was demonstrated that progressive hypoxemia is probably an important cause of death, and oxygen should be the first treatment given to any patient with acute severe asthma.

\section{Recommendation}

2. All children with an acute asthma exacerbation should receive humidified oxygen to achieve or maintain normal oxygen saturation. Level of evidence expert opinion: benefits were 
substantial; strength of recommendation: strong $(6 \nabla)$.

Drugs

Drugs normally used in acute asthma and the corresponding doses are reported in Table III.

\section{Beta, agonists}

The short-acting beta 2 agonists represent the first choice treatment in acute asthma exacerbation for their bronchodilator effect.

Continuous inhaled beta-agonist treatment (CBA) does not offer advantages compared to intermittent treatment. (11-12) As regards the side effects, intermittent inhaled beta- agonists, compared to $\mathrm{CBA}$, increased the heart rate from baseline (30 beats/min $v_{s} 18$ beats/min), but tremor was equally common in both treatment groups $(\mathrm{RR}=0.56$, IC $95 \%$ from 0.21 to 1.40 ) (11).

The administration of beta 2 agonist using an MDI with spacer is an effective alternative to nebulizers for the treatment of children with severe or potentially severe acute asthma in the emergency department (13). The dose of beta2 agonists administered by MDI with spacer must be guided by the severity of the acute asthma exacerbation as reported in Table III.

When there is a scarce response to inhaled beta2 agonist, salbutamol may be administered intravenously, under close clinical monitoring, in children admitted to the ED (14).

\section{- Current unlicensed and off-label use}

Salbutamol standard pMDIs and inhalation solution are indicated for the relief of bronchospasm in children over 2 years of age; although salbutamol is widely used in children under 2 years of age.

\section{Recommendation}

3. Nebulised salbutamol should be administered every 20-30 minutes and at high cumulative doses in severe acute asthma exacerbation. Level of evidence: high; benefit: substantial; strength of recommendation: strong (1A)

4. Continuous inhaled beta-agonist treatment does not offer advantages compared to intermittent treatment. Level of evidence: moderate; benefit: substantial; strength of recommendation: strong.
5. In moderate acute asthma exacerbation the MDI with spacer is the optimal device for providing beta2 agonists. Level of evidence: high; benefit: substantial; strength of recommendation: strong (1A).

6. The dose of beta2 agonists administered by MDI with spacer must be guided by the severity of the acute asthma exacerbation, at least 24 sprays (200-400 mcg), every 20-30', with variable frequency, depending on the clinical response. Level of evidence: high; benefit: substantial; strength of recommendation: strong (1B)

7. Salbutamol (administered intravenously) is recommended as an alternative to conventional therapy in unresponsive cases of life-threatening asthma. Level of evidence: moderate-high; benefit: substantial; strength of recommendation: strong $(2 \mathrm{~B})$

\section{Anticholinergic drugs}

Anticholinergic drugsareslowerbronchodilatators than beta2 agonists; nevertheless, they are synergic. Ipratropium bromide is commonly used in children.

\section{Ipratropium bromide}

For children over 2 years of age, and in cases of moderate and severe asthma exacerbation, the addition of inhaled ipratropium bromide in multiple doses to beta2 agonists should be considered (15). A short cut review of 148 papers, carried out to establish whether adding inhaled anti-cholinergics to beta-agonists improves outcome in the treatment of acute childhood asthma, concluded that anticholinergics reduce time to recovery and discharge, and may reduce admissions for moderate to severe asthmatic children (14). In children under 2 years, ipratropium bromide added to beta 2 agonists is less effective (17). Dosage for children are reported in Table III.

\section{- Current unlicensed and off-label use}

Aerocaps of ipratropium bromide are not recommended for asthmatic children under 12 years of age. A CFC-free inhaler is suggested in asthmatic children 6 to 12 years of age or in children under 6 (a lower age limit is not specified). 


\section{Recommendation}

8. For children over 2 years of age, in cases of moderate and severe asthma exacerbation inhaled ipratropium bromide should be added to beta2 agonists. Level of evidence: high; benefit: substantial; strength of recommendation: strong (1A).

\section{Corticosteroids (CS)}

The early use of systemic corticosteroids (SCS) in acute asthma exacerbation may reduce the frequency of hospitalizations and prevent a relapse of symptoms after initial administration.

SCS must be administered early in the treatment of moderate and severe acute asthma exacerbation. The SCS need at least 2-4 hours to determine a significant clinical improvement. There are no significant differences between the methods of administration (oral or IV), although oral administration is preferred because is less invasive and less expensive (18-19). The dosage of oral corticosteroids is reported in Table III. Lower doses of steroids may be equally effective in children, with fewer side effects (20). Experts recommend 3-5 days of therapy, excluding the need to taper the SCS at the end of the therapy (21).

The scientific evidence is currently insufficient to recommend the use of high dose inhaled corticosteroids (ICS) as an alternative or in addition to oral steroids in acute asthma exacerbation. (22)

In a recent meta-analysis (23), Rodrigo et al. evaluated the effectiveness of ICS in the first 4 hours from the beginning of treatment in adults and children (4 SCR, 285 patients) with acute severe asthma. Patients subjected to ICS showed a more rapid clinical improvement than those subjected to placebo or to SCS, with a $40 \%$ reduction of the risk of being admitted in the ED in the first 4 hours.

\section{- Current unlicensed and off-label use}

None when used in asthma

\section{Recommendation}

9. CSs (oral or IV) should be administered early in the treatment of moderate and severe asthma exacerbations, with clinical improvement usually not before 4 hours after administration. Level of evidence: high; benefit: substantial; strength of recommendation: strong (1A).

10. The use of ICS as an alternative or in addition to oral steroids in acute asthma exacerbation. ICS is not recommended. Level of evidence: moderate; benefit: intermediate; strength of recommendation: strong (3C).

\section{Aminophylline}

The association of aminophylline IV to beta2 agonist and of aminophylline IV to beta2 agonist and SCS in severe asthma exacerbation does not offer significant advantages and it can even cause serious side effects; nevertheless some patients benefit from this drug. (24)

\section{- Current unlicensed and off-label use}

The use of aminophylline IV in children under 6 months of age is generally not recommended.

\section{Recommendation}

11. Aminophylline therapy is not recommended in acute asthma exacerbations in the ED. Level of evidence high; benefit intermediate; strength of recommendation strong (1A).

12. Aminophylline can be taken into consideration, in addition to the usual treatment, in patients with respiratory failure and those showing a previous satisfactory effect using these drugs. Level of evidence: weak; benefit: conflicting; strength of recommendation based on expert opinion.

\section{Epinephrine}

Inhaled epinephrine does not show any additional benefit compared with beta- 2 agonist in the treatment of acute asthma exacerbation and can cause side effects, especially in hypoxemic patients (25). Dosage for children is reported in Table III.

\section{- Current unlicensed and off-label use}

None when used in asthma

\section{Recommendation}

12. Epinephrine (administered subcutaneously or intravenously) is not recommended in acute asthma exacerbations, it can be used as an alternative after I.V. beta-2-agostinst therapy in unresponsive cases of life-threatening asthma. Level of evidence: weak; benefit: little; strength 
of recommendation: strong (4D).

\section{Leukotriene Receptor Antagonists (LRAs)}

The effect of LRAs in acute asthma exacerbation is, however, not confirmed and leukotriene antagonists are not yet established as agents for acute management in moderate-severe asthma exacerbations in ED. (26)

\section{Recommendation}

13. The use of montelukast is not recommended in children with acute asthma exacerbation. Level of evidence: weak; benefit: little; strength of recommendation: strong.

\section{Magnesium sulfate}

Experiences in children are limited and relate to a single IV dose, 25-75 mg / $\mathrm{kg}$ in 20' (27); data on safety and efficacy of using repeated doses is not currently available.

Recent reports indicate the use of isotonic solution of $\mathrm{MgSO} 4$ with nebulizer in addition to bronchodilator in severe asthma; it improves lung function, but not the percentage of hospitalizations (28).

\section{- Current unlicensed and off-label use}

This drug is not licensed for acute asthma exacerbations.

\section{Recommendation}

14. IV Magnesium sulfate (MgSO4) is not recommended in children with severe asthma exacerbation. It use can be considered in a single dose in non-responsive children and/or with FEV1 less than $60 \%$ after one hour of therapy. Level of evidence: high, benefit: little, strength of recommendation: strong (1B).

\section{Heliox}

Helium is a low density gas; therefore the inhalation of a mixture containing helium/oxygen (Heliox) can reduce respiratory fatigue and improve ventilation in patients with obstruction of airways. A helium-oxygen mixture $(70 \% / 30 \%)$ can be used as a carrier for administration of inhaled bronchodilators in patients with life threatening asthma, after one hour of conventional therapy.
This gas can be used, as an alternative to oxygen, in severe asthma exacerbation that does not respond to initial treatment. (29)

\section{Recommendation}

15. The use of Heliox as an alternative to oxygen therapy is not recommended in acute asthma. Level of evidence: moderate; benefit: little; strength of recommendation: strong (3C).

\section{DEVICES FOR INHALATION IN ACUTE ASTHMA EXACERBATION}

Nebulizers, dry powder inhalers (DPI) and MDI are the devices used for inhalation in acute asthma exacerbations. Use of MDIs with spacers, with/ without facemasks, is recommended for paediatric patients. For the effective use of MDIs with spacers, it is crucial that the doctor chooses the device that is best suited to each patient and that the patient is trained on its correct use (30).

\section{Recommendation}

16. Use of MDIs with spacers, with/without facemasks, is recommended for paediatric patients with acute asthma exacerbation. Level of evidence: moderate, benefit: substantial, strength of recommendation: strong

\section{Hydro-electrolytic balance}

Some children during acute asthma exacerbations have variable dehydration and can require adequate hydration. Intravenous is preferred if the patient vomits, or during severe respiratory distress. An excessive intake of fluid must be avoided to prevent pulmonary oedema. (31)

Salbutamol infusions, aminophylline and steroids can cause a decrease in blood potassium concentrations, with possible side effects on muscle contraction and cardiac rhythm; IV potassium should be administered, according to the results of regular blood controls. (32)

\section{Recommendation}

17. In all patients with acute asthma exacerbations in the ED dehydration should be prevented, especially if IV therapy for severe asthma is necessary. Level of evidence expert opinion 
Table I. Key to evidence statements and grades of recommendations.

\begin{tabular}{|c|c|}
\hline & LEVELS OF EVIDENCE \\
\hline 1 & Well-conducted meta-analyses, systematic reviews, or RCTs with a low risk of bias \\
\hline 2 & Meta-analyses, systematic reviews, or RCTs with a high risk of bias \\
\hline 3 & High quality systematic reviews of case control or cohort or studies \\
\hline 4 & $\begin{array}{l}\text { Case control or cohort studies with a high risk of confounding or bias and a significant risk } \\
\text { that the relationship is not causal }\end{array}$ \\
\hline 5 & Non-analytic studies, e.g. case reports, case series \\
\hline 6 & Expert opinion \\
\hline & GRADES OF RECOMMENDATIONS \\
\hline A & $\begin{array}{l}\text { At least one meta-analysis, systematic review, or RCT rated as } 1 \text {, and directly applicable to } \\
\text { the target population; or a body of evidence consisting principally of studies rated as } 1 \text {, } \\
\text { directly applicable to the target population, and demonstrating overall consistency of } \\
\text { results. }\end{array}$ \\
\hline $\mathrm{B}$ & $\begin{array}{l}\text { A body of evidence including studies rated as } 2-3 \text {, directly applicable to the target } \\
\text { population, and demonstrating overall consistency of results; or extrapolated evidence from } \\
\text { studies rated as } 1 \text {. }\end{array}$ \\
\hline $\mathrm{C}$ & $\begin{array}{l}\text { A body of evidence including studies rated as } 3-4 \text {, directly applicable to the target } \\
\text { population and demonstrating overall consistency of results; or extrapolated evidence from } \\
\text { studies rated as } 3 \text {. }\end{array}$ \\
\hline $\mathrm{D}$ & Evidence level 5 or 6 or extrapolated evidence from studies rated as 3 . \\
\hline$\nabla$ & $\begin{array}{l}\text { Good practice points: recommended best practice based on the clinical experience of the } \\
\text { guideline development group. }\end{array}$ \\
\hline
\end{tabular}

benefit: substantial; strength of recommendation: strong $(6 \square)$

Endotracheal intubation and invasive ventilation Endotracheal intubation should be carried out on patients who, despite correct medical therapy and $\mathrm{O} 2$ administration, present:

- a progressive increase of $\mathrm{PaCO} 2$

- an exhaustion of respiratory muscle contraction

- persistent hypoxia

- alteration of conscience.

The choice of endotracheal intubation is not based on simple evaluation of numerical parameters, but on the clinical judgement of an expert team.

Except for respiratory arrest, there are no absolute criteria for these procedures. The decision of carrying out intubation on a patient cannot be simply based on the evaluation of numerical parameters, but on the clinical judgement of an expert team, including an anaesthesiologist (33).

\section{Recommendation}

18. In cases of severe asthma exacerbation endotracheal intubation and invasive ventilation should be considered. Level of evidence expert opinion, benefit: substantial, strength of recommendation: strong $(6 \nabla)$.

\section{OPERATIVE DECISIONS}

The level of treatment of an acute asthma exacerbation depends on its severity and on the response to therapy. The management of acute asthma exacerbations starts at home. Most patients show a gradual improvement after conventional therapy. A minority of them may present a progressive clinical deterioration (34) and, if a more aggressive treatment is ineffective, they should be 
Table II. Grades of severity of acute asthma exacerbations*.

\begin{tabular}{|c|c|c|c|c|}
\hline \multirow{2}{*}{ Parameters } & \multicolumn{4}{|c|}{ Grade of severity } \\
\hline & Mild & Moderate & Severe & $\begin{array}{l}\text { Risk of forthcoming } \\
\text { respiratory arrest }\end{array}$ \\
\hline Child talks in & Sentences & Phrases & Words & - \\
\hline Respiratory rate & Normal & Increased & Increased & Bradypnea \\
\hline Colour & Normal & Pallor & Pallor/Cyanosis & Cyanosis \\
\hline Alertness & Normal & Usually agitated & Usually agitated & Drowsy or confused \\
\hline Wheezing & End-Expiration & Expiration & $\begin{array}{c}\text { Both } \\
\text { Expiration/Inspiration }\end{array}$ & No audible wheezing \\
\hline $\begin{array}{c}\text { Use of accessory } \\
\text { muscles }\end{array}$ & Usually not & Moderate & Severe & Paradoxical breathing \\
\hline $\begin{array}{l}\text { Pulse rate } \\
\text { (pulse/min) }\end{array}$ & Normal & Increased & Increased & Bradycardia \\
\hline $\begin{array}{l}\text { PEF - FEV1 } \\
\% \text { predicted or } \\
\text { personal best }\end{array}$ & $>80 \%$ & $60-80 \%$ & $<60 \%$ & Not executable \\
\hline $\mathrm{SaO} \%$ (on air) & $>95 \%$ & $92-95 \%$ & $<92 \%$ & $<90 \%$ \\
\hline $\mathrm{PaCO} 2$ (mmHg) & $<38$ & $38-42$ & $>42$ & $>42$ \\
\hline
\end{tabular}

*Note: The presence of several parameters, but not necessarily all of them, indicates the grade of severity of the exacerbation.

Normal breathing rates in conscious children:

\begin{tabular}{ll}
\hline 2 months & $<60 / \mathrm{min}$ \\
$2-12$ months & $<50 / \mathrm{min}$ \\
$1-5$ years & $<40 / \mathrm{min}$ \\
$6-9$ years & $<30 / \mathrm{min}$ \\
$10-14$ years & $<20 / \mathrm{min}$
\end{tabular}

Limits of normal pulse rate in children:

$0-12$ months $<160 / \mathrm{min}$

$>1-2$ years $\quad<120 / \mathrm{min}$

$>2-8$ years $\quad<110 / \mathrm{min}$

sent to the Emergency Department (ED).

\section{INDICATIONS FOR HOSPITALIZATION}

Panel members do not agree on predictive criteria of evolution of an acute asthmatic episode. For this reason, it is recommended that the decision of hospitalization should be made after the evaluation of anamnestic, clinical and functional parameters and after a continuous monitoring of the patient. Absolute indications for hospitalization are: signs and symptoms of acute respiratory failure, worsening of clinical parameters after bronchodilator treatment, $\mathrm{SatO} 2<92 \%$ after bronchodilator treatment, concomitant complications (pneumothorax, atelectasies, etc.) (Table IV). 
Table III. Drugs and dosages used for treatment of acute asthma exacerbation.

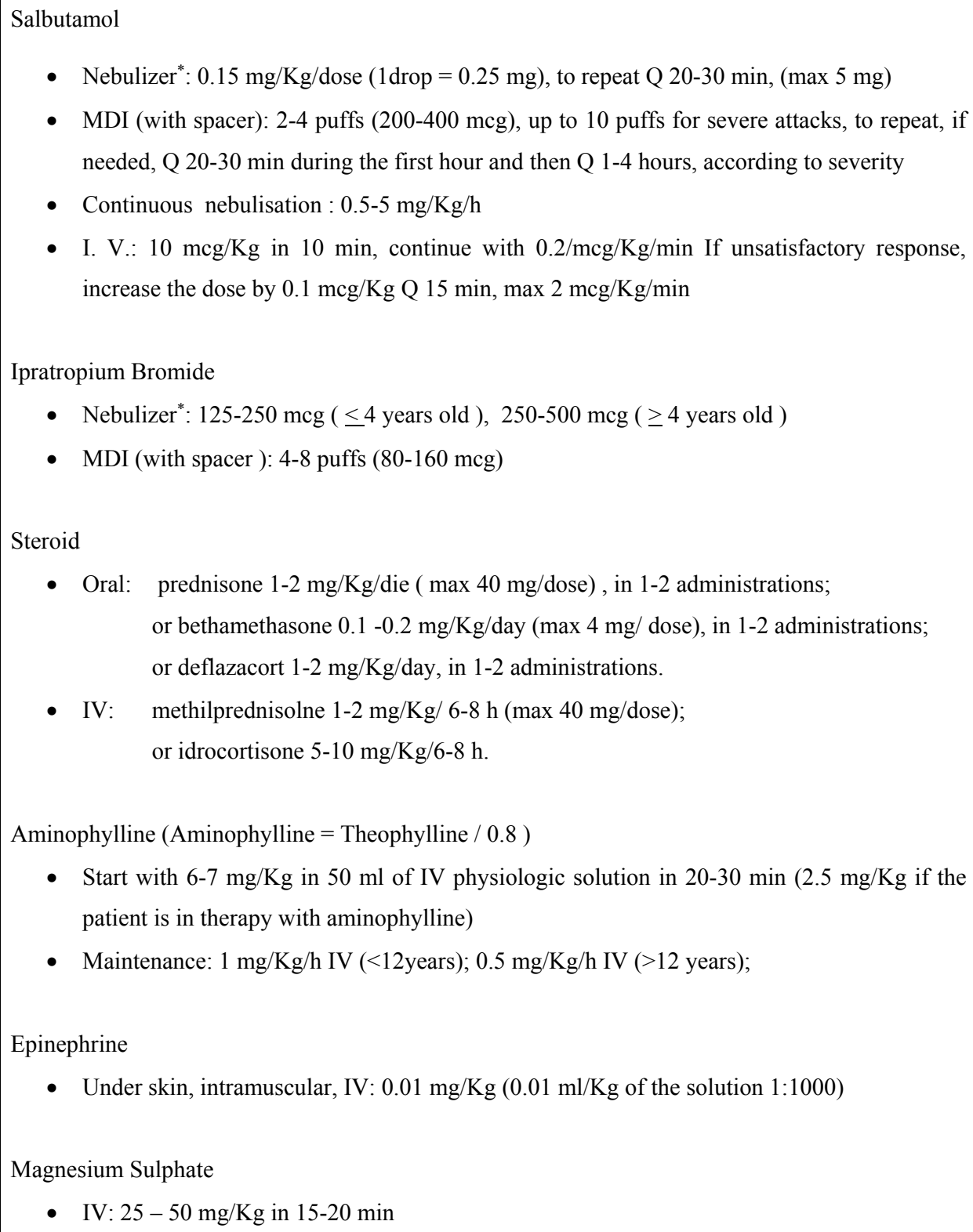
needed, Q 20-30 min during the first hour and then Q 1-4 hours, according to severity

- Continuous nebulisation : 0.5-5 mg/Kg/h

- I. V.: $10 \mathrm{mcg} / \mathrm{Kg}$ in $10 \mathrm{~min}$, continue with $0.2 / \mathrm{mcg} / \mathrm{Kg} / \mathrm{min}$ If unsatisfactory response, increase the dose by $0.1 \mathrm{mcg} / \mathrm{Kg}$ Q $15 \mathrm{~min}$, $\max 2 \mathrm{mcg} / \mathrm{Kg} / \mathrm{min}$

Ipratropium Bromide

- Nebulizer*: $125-250 \mathrm{mcg}$ ( $\leq 4$ years old ), $250-500 \mathrm{mcg}$ ( $\geq 4$ years old )

- $\quad$ MDI (with spacer ): 4-8 puffs (80-160 mcg)

Steroid

- Oral: prednisone $1-2 \mathrm{mg} / \mathrm{Kg} / \mathrm{die}$ ( $\max 40 \mathrm{mg} / \mathrm{dose}$ ), in 1-2 administrations; or bethamethasone $0.1-0.2 \mathrm{mg} / \mathrm{Kg} /$ day ( $\max 4 \mathrm{mg} /$ dose), in 1-2 administrations; or deflazacort 1-2 mg/Kg/day, in 1-2 administrations.

- IV: methilprednisolne 1-2 mg/Kg/ 6-8 h ( $\max 40 \mathrm{mg} /$ dose); or idrocortisone $5-10 \mathrm{mg} / \mathrm{Kg} / 6-8 \mathrm{~h}$.

Aminophylline (Aminophylline $=$ Theophylline / 0.8$)$

- Start with 6-7 mg/Kg in $50 \mathrm{ml}$ of IV physiologic solution in $20-30 \mathrm{~min}(2.5 \mathrm{mg} / \mathrm{Kg}$ if the patient is in therapy with aminophylline)

- Maintenance: $1 \mathrm{mg} / \mathrm{Kg} / \mathrm{h} \mathrm{IV} \mathrm{(<12years);} 0.5 \mathrm{mg} / \mathrm{Kg} / \mathrm{h} \mathrm{IV} \mathrm{(>12} \mathrm{years);}$

Epinephrine

- Under skin, intramuscular, IV: $0.01 \mathrm{mg} / \mathrm{Kg}(0.01 \mathrm{ml} / \mathrm{Kg}$ of the solution $1: 1000)$

Magnesium Sulphate

- IV: $25-50 \mathrm{mg} / \mathrm{Kg}$ in $15-20 \mathrm{~min}$

*Nebulised in $3 \mathrm{ml}$ of saline solution

\section{RECOMMENDATION ON DISCHARGE FROM ED}

The discharge of a patient should be decided after a global evaluation of clinical and functional parameters (35-36).

When the patient leaves hospital, the symptoms must be minimal, $\mathrm{PEF}>75 \%$; it is necessary to check the child's ability to correctly operate the inhaler, to continue treatment with beta 2 agonists for at least a week, to consider the use of ICS, to deliver written information on the treatment of acute exacerbations, and to plan a control visit with general practitioner within a week and in a 
Table IV. Operative decisions.

\section{MODERATE ASTHMA EXACERBATION}

- Salbutamol: inhalation, spray (with spacer) 2-4 puffs (200-400 mcg) max 10 puffs if more severe, or nebulizer $(0.15 \mathrm{mg} / \mathrm{Kg} /$ dose, $1 \mathrm{drop}=0.25 \mathrm{mg})$, repeat Q $20 \mathrm{~min}$, as needed, up to 3 doses, adding Ipratropium bromide spray (with spacer), 4-8 puffs (80-160 mcg) o nebulizer, 125-250 mcg ( $<4$ yrs of age) and $250-500 \mathrm{mcg}(>4$ yrs of age $)$

- Steroid: oral prednisone $1-2 \mathrm{mg} / \mathrm{Kg} / \mathrm{die}(\max 40 \mathrm{mg} / \mathrm{dose})$ once or twice daily or betametasone $0.1-0.2$ $\mathrm{mg} / \mathrm{Kg} / \mathrm{die}(\max 4 \mathrm{mg} / \mathrm{dose}$ ) once or twice daily or deflazacort 1-2 mg/Kg/die, once or twice daily.

a) Clinical improvement: progressively reduce the frequency of salbutamol and ipratropium bromide, then continue only with salbutamol and steroids orally.

b) Clinical deterioration: Admission to ED.

Repeat salbutamol with ipratropium bromide, Q 20 min up to 3 doses

Continue steroids orally

O2 therapy

b1) if clinical improvement starts, gradually reduce treatment according to clinical response.

b2) if clinical conditions deteriorate, treat as a severe asthma exacerbation.

\section{SEVERE ASTHMA EXACERBATION}

- Salbutamol: inhalation, spray (with spacer) 2-4 puffs(200-400 mcg) max 10 puffs, or nebulizer $(0.15$ $\mathrm{mg} / \mathrm{Kg} /$ dose), Q 20 min up to 3 doses, together with Ipratropium bromide MDI (with spacer), 4-8 puffs (80-160 mcg), or nebulizer, $125-250 \mathrm{mcg}(<4$ yrs of age $)$ and $250-500 \mathrm{mcg}(>4 \mathrm{yrs}$ of age $)$

- Steroid: oral prednisone $1-2 \mathrm{mg} / \mathrm{Kg} / \mathrm{die}(\max 40 \mathrm{mg} / \mathrm{dose}$ ) once or twice daily, or betametasone $0.1-0.2$ $\mathrm{mg} / \mathrm{Kg} /$ die $(\max 4 \mathrm{mg} /$ dose) once or twice daily, or deflazacort $1-2 \mathrm{mg} / \mathrm{Kg} / \mathrm{die}$, once or twice daily; systemic metilprednisolone $1-2 \mathrm{mg} / \mathrm{Kg} / 6-8 \mathrm{~h}$ ( $\max 40 \mathrm{mg} / \mathrm{dose})$ or idrocortisone $5-10 \mathrm{mg} / \mathrm{Kg} / 6-8 \mathrm{~h}$

- O2 therapy

- Admission to ED

a) Clinical improvement: gradually reduce the frequency of administration of salbutamol and ipratropium bromide (initially Q hour for 3 times).

Continue steroids and $\mathrm{O} 2$, if $\mathrm{SaO} 2<95 \%$

b) Clinical deterioration: repeat inhalations Q 20 min up to 3 doses.

Continue steroids and $\mathrm{O} 2$

b1) if clinical improvement starts, gradually reduce treatment according to clinical response

b2) if clinical deterioration continues begin more aggressive treatment:

- IV Aminophylline: $6-7 \mathrm{mg} / \mathrm{Kg}$ in $50 \mathrm{ml}$ of saline solution in $20-30 \mathrm{~min}(2.5 \mathrm{mg} / \mathrm{Kg}$, if patient is using theophylline); maintenance: $1 \mathrm{mg} / \mathrm{Kg} / \mathrm{h}(\leq 12 \mathrm{yrs}$ of age $)$ or $0.5 \mathrm{mg} / \mathrm{Kg} / \mathrm{h}(>12 \mathrm{yrs}$ of age $)$

- IV Salbutamol: $10 \mathrm{mcg} / \mathrm{Kg}$ (bolus dose) in $10 \mathrm{~min}$, followed by infusion of $0.2 \mathrm{mcg} / \mathrm{Kg} / \mathrm{min}$. If no response, increase the dose of $0.1 \mathrm{mcg} / \mathrm{Kg}$ Q $15 \mathrm{~min}, \max 2 \mathrm{mcg} / \mathrm{Kg} / \mathrm{min}$.

- $\quad$ Check blood gases to evaluate admission to ICU 
Specialist Asthma Centre within a month.

\section{CONCLUSIONS}

This update on acute asthma exacerbations in children is based on evidence statements and grades of recommendations.

Although several asthma guidelines providing helpful information are available, this paper aims to underline some aspects of asthma management in children: for example the association of ipratropium bromide and beta 2 agonists in acute asthma and the possible use of magnesium sulphate. Another topic is the current use of unlicensed and off-label drugs, which is frequent in children and potentially harmful. Their use varies from country to country, depending on local laws and regulations. This last aspect may be a potential starting point for clinical research in order to improve the treatment of children with acute asthma exacerbations.

The best strategy, in case of acute asthma exacerbation, is to start treatment at home with a rapid pharmacologic intervention to prevent the worsening of symptoms and to reduce emergency visits and hospitalizations. When symptoms progressively deteriorate despite pharmacological treatment, it is mandatory to send the patient to ED. Close cooperation between the paediatrician, general practitioner, ED staff, nursing staff and, wherever possible, the child and his family is essential for the appropriate management of this kind of emergency. Diagnostic and therapeutic algorithms simplify the clinical management of acute asthma and they are a useful educational tool for every professional caregiver involved.

\section{ACKNOWLEDGEMENTS}

We thank M. Osti, A. Palma, S. Santucci, R. Sassi, A. Villani and R. Zanini for their help in writing this paper.

\section{REFERENCES}

1. British Thoracic Society, Scottish Intercollegiate Guidelines Network. British Guideline on the Management of Asthma. Available at: http://ww w.enterpriseportal2.co.uk/filestore/bts/asthma

up datenov05.pdf. Date last updated: 2005. Date last accessed: August 29, 2008.

2. National Health, Lung and Blood Institute. Global Initiative for Asthma (GINA). Global Strategy for Asthma Management and Prevention. Publication n. 95-3659, 1995 Bethesda, Maryland, revised 2006. Available at: http://www.ginasthma.org.

3. National Asthma Education and Prevention Program Expert Panel Report 3 (EPR-3): Guidelines for the Diagnosis and Management of Asthma-Summary Report 2007. J Allergy Clin Immunol 2007; 120(S): 94-138.

4. Carroll CL, Schramm CM, Zucker AR. Severe exacerbations in children with mild asthma: characterizing a pediatric phenotype. J Asthma 2008; 45: 513-17.

5. Boychuk RB, Yamamoto LG, DeMesa CJ, Kiyabu KM. Correlation of initial emergency department pulse oximetry values in asthma severity classes (steps) with the risk of hospitalization. Am J Emerg Med 2006; 24:48-52.

6. Ducharme FM, Chalut D, Plotnick L, Savdie C, Kudirka D, Zhang X, Meng L, McGillivray D. The Pediatric Respiratory Assessment Measure: a valid clinical score for assessing acute asthma severity from toddlers to teenagers. J Pediatr 2008; 152:476-80.

7. Reddel HK, Taylor DR, Bateman ED, et al: American Thoracic Society/European Respiratory Society Task Force on Asthma Control and Exacerbations. An official American Thoracic Society/European Respiratory Society statement: asthma control and exacerbations: standardizing end points for clinical asthma trials and clinical practice. Am J Respir Crit Care Med 2009; 180:59-99.

8. Chien JW, Ciufo R, Novak R, Skowronski M, Nelson J, Coreno A, McFadden ER Jr. Uncontrolled oxygen administration and respiratory failure in acute asthma. Chest 2000; 117:728-33.

9. Rodrigo GJ, Rodriquez Verde M, Peregalli V, Rodrigo C. Effects of short-term $28 \%$ and $100 \%$ oxygen on $\mathrm{PaCO} 2$ and peak expiratory flow rate in acute asthma: a randomised trial. Chest 2003; 124:1312-7.

10. Inwald D, Roland M, Kuitert L, McKenzie SA, Petros A. Oxygen treatment for acute severe asthma. BMJ 2001; 323:98-100.

11. Camargo CA, Spooner CH, Rowe BH. Continuous 
versus intermittent beta-agonists for acute asthma. Cochrane Database Syst Rev 2003; (4):CD001115.

12. Khine H, Fuchs SM, Saville AL. Continuous vs intermittent nebulized salbutamol for emergency management of asthma. Academ Emerg Med 1996; 3:1019-24.

13. Sannier N, Timsit S, Cojocaru B, Leis A. Metereddose inhaler with spacer $v s$. nebulisation for severe and potentially severe acute asthma treatment in the Pediatric Emergency Department. Arch Pediatr 2006; 13:238-44.

14. Roberts G, Newsom D, Gomez K, et al: North West Thames Asthma Study Group. Intravenous salbutamol bolus compared with aminophylline infusion in children with severe asthma: a randomised controlled trial. Thorax 2003; 58:306-10.

15. Rodrigo GJ, Castro-Rodriguez JA. Anticholinergics in the treatment of children and adults with acute asthma: a systematic review with meta-analysis. Thorax 2005; 60:740-6.

16. Munro A, Maconochie I. Best evidence topic reports. Beta-agonists with or without anti-cholinergics in the treatment of acute childhood asthma? Emerg Med J 2006; 23:470-74.

17. Everard ML, Bara A, Kurian M, Elliott TM, Ducharme F, Mayowe V. Anticholinergic drugs for wheeze in children under the age of two years. Cochrane Database Syst Rev 2005; (3):CD001279.

18. Becker JM, Arora A, Scarfone RJ. Oral versus intravenous corticosteroids in children hospitalized with asthma. J Allergy Clin Immunol 1999; 103:58690.

19. Barnett PL, Caputo GL, Maskin M. Intravenous versus oral corticosteroids in the management of acute asthma in children. Ann Emerg Med 1997; 29: 212-17.

20. Kayani S, Shannon DC. Adverse behavioral effects of treatment for acute exacerbation of asthma in children: a comparison of two doses of oral steroids. Chest 2002; 122:624-28.

21. O'Driscoll BR, Kalra S, Wilson M, Pickering CA, Carroll KB, Woodcock AA. Double-blind trial of steroid tapering in acute asthma. Lancet 1993; 341: 324-27.

22. Edmonds ML, Camargo CA Jr, Brenner BE, Rowe $\mathrm{BH}$. Replacement of oral corticosteroids with inhaled corticosteroids in the treatment of acute asthma following emergency department discharge: a metaanalysis. Chest 2002; 121:1798-805.

23. Rodrigo GJ. Rapid effects of inhaled corticosteroids in acute asthma. An evidence-based evaluation. Chest 2006; 130:1301-10.

24. Mitra A, Bassler D, Goodman K, Lasserson TJ, Ducharme FM. Intravenous aminophylline for acute severe asthma in children over two years receiving inhaled bronchodilators. Cochrane Database Syst Rev 2005; (2):CD001276.

25. Rodrigo GJ, Nannini LJ. Comparison between nebulised adrenaline and beta 2 agonists for treatment of acute asthma. A meta-analysis of randomised trials. Am J Emerg Med 2006; 24:217-22.

26. Mahajan P, Haritos D, Rosenberg N, Thomas R. Comparison of nebulised magnesium plus salbutamol to nebulised salbutamol plus saline in children with mild to moderate asthma. J Emerg Med 2004; 27:215.

27. Kim IK, Phrampus E, Venkataraman S, Pitetti R, Saville A, Corcoran T, Gracely E, Funt N, Thompson A. Helium/Oxygen-driven salbutamol nebulisation in the treatment of children with moderate to severe asthma exacerbations: a randomised, controlled trial. Pediatrics 2005; 116:1127-33.

28. Dolovich MB, Ahrens RC, Hess DR, Anderson P, Dhand R, Rau JL, Smaldone GC, Guyatt G; American College of Chest Physicians; American College of Asthma, Allergy, and Immunology. Device selection and outcomes of aerosol therapy: Evidence-based guidelines: American College of Chest Physicians/American College of Asthma, Allergy, and Immunology. Chest 2005; 127:335-71.

29. Bahna SL, Kaushik SP. Water and electrolyte status in children with acute asthma. J Asthma 1984; 21: 73-9.

30. Parr JR, Salama A, Sebire P. A survey of consultant practice: intravenous salbutamol or aminophylline for acute severe childhood asthma and awareness of potential hypokalemia. Eur J Pediatr 2006; 165:32325.

31. Soroksky A, Stav D, Shpirer I. A pilot prospective, randomised, placebo-controlled trial of bi-level positive airway pressure in acute asthmatic attack. Chest 2003; 123:1018-25. 
32. Stempel DA, McLaughlin TP, Stanford RH. Treatment patterns for pediatric asthma prior to and after emergency department events. Pediatr Pulmonol 2005; 40:310-15.

33. Harvey S, Forbes L, Jarvis D, Price J, Burney P. Accident and emergency departments are still failing to assess asthma severity. Emerg Med J 2003; 20:
329-31.

34. Walsh-Kelly CM, Kelly KJ, Drendel AL, Grabowaski L, Kuhn EM. Emergency Department Revisits for Pediatric Acute Asthma Exacerbations: Association of Factors identified in an emergency department asthma tracking system. Pediatr Emerg Care 2008; 24: 505-10. 